\title{
Analysis and Suggestions on the Implementation Effect of Medium and Long-Term Incentive Policies in State- Owned Science and Technology Enterprises
}

\author{
Yunfei $\mathrm{Xu}^{1, *}$ Dan Wang ${ }^{2}$ Yan Chang ${ }^{3}$ Luanying $\mathrm{Wu}^{4}$ \\ 1,2,3,4 State Grid Energy Research Institute Co. LTD, Changping, 102209, Beijing, China \\ ${ }^{*}$ Corresponding author. Email: xuyunfei@sgeri.sgcc.com.cn
}

\begin{abstract}
The implementation of medium-and long-term incentive policies for state-owned scientific and technological enterprises is of great significance to further mobilize the enthusiasm and creativity of scientific and technological talents, accelerate the transformation of scientific and technological achievements and stimulate the innovation of state-owned enterprises. Through combing 16 medium and long-term incentive policy documents and investigating and interviewing the implementation of medium and long-term incentives in 12 central enterprise groups, this paper found certain practical challenges and obstacles in the process of implementing the policy, which are mainly manifested as follows: firstly, the top-level design and the policy system is not perfect; secondly, the scope and constraints of policy implementation need to be further improved; thirdly, the supervision and evaluation of medium and long-term incentive policies are not in place. Based on the analysis of the effects and reasons of the implementation of the medium and long-term incentive policies in state-owned science and technology enterprises, this paper puts forward opinions and suggestions from various ministries and central enterprises.
\end{abstract}

Keywords: State-owned scientific and technological enterprises, Medium and long-term incentive mechanism, policy implementation

\section{INTRODUCTION}

Science and technology are the foundation of national prosperity, and innovation is the soul of national progress. Since the 18th National Congress of the Communist Party of China, General Secretary Xi Jinping has attached great importance to scientific and technological innovation, vigorously promoted the implementation of innovation-driven development strategy, and placed innovation at the core of the overall development of the country. The Fifth Plenary Session of the 19th CPC Central Committee put forward that innovation should be the core position in the overall situation of China's modernization, and speed up the construction of a powerful country in science and technology. General Secretary Xi Jinping emphasized the need to strengthen the national strategic scientific and technological strength, enhance the technological innovation capability of enterprises, stimulate the innovation vitality of talents, and improve the system and mechanism of scientific and technological innovation. Raise the importance of scientific and technological innovation to a new historical height. As the "main force" and "vanguard" of the national science and technology innovation force, state-owned science and technology enterprises should give full play to the role of the national team and make breakthroughs in the field of science and technology innovation. It is urgent to stimulate the vitality of talents by strengthening medium and long-term incentives to help raise science and technology innovation to a new level [1].

\section{THE EVOLUTION AND BREAKTHRO- UGH OF MEDIUM AND LONG-TERM INCENTIVE POLICIES FOR STATE- OWNED SCIENCE AND TECHNOLOGY ENTERPRISES}

State-owned scientific and technological enterprises have always been the vanguard of the reform in the medium and long-term incentive field of state-owned enterprises. Since February 2010, the Ministry of Finance and the Ministry of Science and Technology issued the Implementation Measures of Equity and 
Dividend Incentive for Enterprises in Zhongguancun National Independent Innovation Demonstration Zone (Caiqi [2010] No.8), the pilot policy of equity and dividend incentive in Zhongguancun has gradually matured and spread to the whole country, the reform of internal income distribution system of enterprises has been deepened, and the medium-and long-term incentive mechanism to stimulate the innovation vitality of talents has been gradually established [2]. Thereafter, The state has successively issued the Interim Measures for Equity and Dividend Incentives of State-owned Science and Technology Enterprises (Caizi [2016] No.4) and the Notice on Doing a Good Job in Equity and Dividend Incentives of Central Science and Technology Enterprises (Guozifa Distribution [2016] No.274), Notice on Expanding the Implementation Scope of Interim Measures for Equity and Dividend Incentives of State-owned Science and Technology Enterprises (Caizi [2018] No.54) A series of documents, such as "Special Action Plan for Deepening Marketoriented Reform and Enhancing Independent Innovation Ability of 100 Science and Technology Enterprises" (State-owned Enterprise Reform Office [2019] No.2) and "Several Policies and Measures to Support Science and Technology Small and Medium-sized Enterprises to Accelerate Innovation and Development in the New Period", provide policy basis and operational guidance for state-owned science and technology enterprises to explore and implement medium-and long-term incentives.

Among them, in terms of incentives and constraints, the policy proposes that the total wages of science and technology enterprises can be managed in a single column, which is not included in the budget base of total wages of group companies and not linked to the economic benefit indicators of group companies, thus increasing the autonomy of enterprises in distribution, opening up a new way for state-owned science and technology enterprises to carry out medium and longterm incentives, and greatly stimulating the enthusiasm and initiative of state-owned enterprises in scientific and technological innovation. The policy points out that the medium-and long-term incentives such as equity incentive, dividend incentive, employee stock ownership, excess profit sharing, virtual equity, and key employees' follow-up investment are vigorously promoted, which provides diversified medium-and longterm incentive schemes for science and technology enterprises and forms a rich and complete medium-and long-term incentive policy system. In stimulating the kinetic energy of scientific and technological innovation, it is proposed to give full play to the main role of scientific and technological enterprises in technological innovation decision-making, $R \& D$ investment and achievement transformation. Judging from the release time and orientation of these policy documents, the state attaches great importance to and encourages scientific and technological innovation, and the urgency and importance of scientific and technological innovation have become increasingly prominent with remarkable results.

\section{THE PROBLEM ANALYSIS OF STATE- OWNED SCIENCE AND TECHNOLOGY ENTERPRISES IN THE LONG-TERM INCENTIVE PRACTICE}

Through interviews, research and seminars, the research group has continuously investigated and tracked the implementation of medium-and long-term incentives of 12 central enterprises including AVIC, China Railway Group and China Electric Power Co., Ltd., and investigated and consulted five experts engaged in medium-and long-term incentives for stateowned science and technology enterprises, including China Academy of Science and Technology Development Strategy, China Petroleum Economic and Technological Research Institute and China-Chile Human Capital Consulting. On this basis, it analyzed and summarized the situation and main problems in the implementation of medium-and long-term incentives. Generally speaking, the long-term incentives of stateowned science and technology enterprises are mainly based on post dividends. The incentive object is mainly the core scientific research and technical personnel, which fully reflects the incentive orientation inclined to scientific and technical personnel, and truly stimulates the vitality and power of scientific and technological innovation within the enterprise. But at the same time, there are some problems and practical obstacles in the implementation of existing policies, which greatly weaken the implementation effect of medium and longterm incentive policies [3].

\subsection{The Top-Level Design and the Policy System Is Not Perfect}

Since Caiqi [2010] No.8 document, the medium-and long-term incentive policies of state-owned science and technology enterprises have been continuously piloted and improved, and the scope of policy implementation has been continuously expanded. However, due to the relatively short implementation period, some policy requirements and clauses are still unsuitable, unclear and uncoordinated.

First, the policy requirements are inconsistent with the guidance of scientific and technological innovation. In the aspect of new business development, the stateowned science and technology enterprises in the new business field are faced with great pressure of survival and development in the initial 3-5 years, which requires continuous investment and is difficult to make profits. According to the regulations of Guozifa Distribution [2016] No.274 and Caizi [2016] No.4, state-owned 
science and technology enterprises in new business areas can not meet the conditions of post dividends, and it is difficult to implement equity incentives, which makes it difficult for them to enjoy medium and longterm incentive policies in the early stage of development. In terms of performance requirements, according to Caizi [2016] No.4 document, the implementation of post dividends "in principle, the annual net profit growth rate should be higher than the average growth level of enterprises in the past three years. Moreover, the net asset appreciation accumulated by the after-tax profits in the past three years should account for more than $10 \%$ of the total net assets of the enterprise at the beginning of the past three years, and the undistributed profit at the beginning of the year when the incentive is implemented is positive. " However, scientific research units mainly focus on scientific and technological research and development, providing support for technological progress and independent innovation of enterprises, rather than taking profit as the consideration standard. If the requirements for business performance are strengthened, it will increase the pressure on business performance of science and technology enterprises, distract the energy of scientific and technological personnel in scientific and technological innovation, and make it difficult to continuously focus on scientific and technological research and development, which is not conducive to basic forward-looking research and major technological research [4].

Second, some policies still have the problems of vague orientation and conflict. The main performances are as follows: (1) It is not clear whether the total amount of equity incentive includes the amount of equity incentive implemented in the early stage of the enterprise. Caizi [2016] No.4 document sets the upper limit for the scale of equity incentive for large, medium and small micro enterprises. However, it is not clear whether the amount of equity incentive implemented by enterprises before implementing equity incentive according to the current policy is limited by the abovementioned upper limit. (2) The deferred tax policy of equity incentive cannot be enjoyed when equity incentive is carried out through the shareholding platform. According to the current tax policy, equity incentive is carried out by means of shareholding platform, and the incentive object cannot enjoy deferred tax payment because it is not an employee of the incentive company, which affects the incentive object's enthusiasm to participate in the plan to a certain extent. (3) The shares of scientific and technological achievements are limited by the number of management legal persons in state-owned enterprises. Through the way of taking shares in scientific and technological achievements, the core technical personnel can start businesses with technology and promote the transformation of scientific and technological achievements projects. Moreover, newly established enterprises can often form a complementary relationship between upstream and downstream technologies with the original enterprises, with good results. However, it is difficult to set up a new enterprise due to the limitation of the number of legal persons in state-owned enterprises.

\subsection{The Scope and Constraints of Policy Implementation Need To Be Further Improved}

The formulation and implementation of medium-and long-term incentive policies is a process from pilot exploration in Zhongguancun to gradual promotion to state-owned science and technology enterprises. However, due to the differences in business characteristics and development stages of state-owned enterprises, there are inevitably unsuitable problems in the process of policy promotion. Although Caizi [2018] No.54 document includes state-owned science and technology small and medium-sized enterprises, unlisted science and technology subsidiaries at all levels funded by state-controlled listed companies and science and technology enterprises invested by enterprises in transformation institutes into the implementation scope of medium-and long-term incentives, the narrow implementation scope of some policies still exists. In addition, some policies have tight constraints, and there is a "one size fits all" situation, without considering the differences of policy implementation targets, and the incentive effect of policy implementation is affected by restrictions.

First, the incentive quota, scope and methods need to be further expanded. In the process of policy implementation, some enterprises are conservative in policy implementation due to caution and fear of the loss of state-owned assets. On the basis of policies, the incentive amount, scope and methods are further restricted, which greatly reduces the incentive intensity and effect, and makes it difficult to meet the medium and long-term incentive needs of enterprises. In terms of incentive quota, according to the policy, the post dividend incentive needs to meet the double limit of the total amount of enterprise and individual dividends, that is, "the annual post dividend incentive amount of an enterprise is not higher than $15 \%$ of the after-tax profit of the current year, and the post dividend income obtained by the incentive object is not higher than $2 / 3$ of its total salary". Although this policy requirement takes into account the fairness of internal salary distribution, it also greatly reduces the incentive intensity, and it is difficult to meet the incentive demand for key core talents, which seriously affects the incentive effect. In the scope of incentive, the coverage of bonus incentive objects is relatively small, and the number of incentive personnel is limited. Moreover, it is difficult for a large number of market-oriented workers to meet the policy 
conditions of post dividends and project income dividends, and they cannot be effectively motivated. At present, only one incentive method can be adopted, and the post dividend incentive and the project income dividend incentive can not be implemented at the same time. Caizi [2016] No.4 document requires that enterprises can only adopt one incentive method and give one incentive to the same incentive object for the same position of scientific and technological achievements or industrialization projects. Due to the differences in post dividends, the implementation conditions of project income dividends, and the principle of total incentive accrual, the selection scope of incentive objects is different. The incentive objects of post dividends are mainly the backbone personnel engaged in basic and forward-looking scientific research and experimental inspectors to solve technical research problems; The incentive object of project dividends is mainly the backbone personnel engaged in product development to solve the problem of market-oriented achievement transformation. If the enterprise can't implement both at the same time, it will lose the fairness of incentive, and at the same time, it can't achieve the purpose of retaining key core talents. It is particularly necessary to implement post dividend incentive and project income dividend incentive at the same time when the incentive targets and objects are different.

Second, there are practical difficulties in the actual operation of project $R \& D$ cost tracing and achievement transformation calculation. In the traceability of project R\&D achievements, scientific and technological enterprises are faced with the problems of difficult traceability and accounting of R\&D costs when implementing dividend incentive of project income. For example, whether the investment of basic forwardlooking projects is taken as research and development cost. The implementation of scientific and technological achievements usually includes $\mathrm{R} \& \mathrm{D}$, incubation, transformation and other stages. The R\&D stage bears the greatest risk, long cycle and high input cost. If all $\mathrm{R} \& \mathrm{D}$ costs are traced back, it is difficult for most stock achievements to achieve net income. Researchers lack confidence in the fulfillment of future incentives, which can not motivate them to actively carry out achievements transformation. The implementation of project income dividend incentives has great resistance, and its promotion effect on achievements transformation is very limited. In the calculation of project achievement transformation, the reward amount of project income dividend is determined based on the net income amount of scientific and technological achievement transformation, but there are great difficulties in actual calculation. In Caizi [2016] No.4, only the net income from technology transfer and licensing is clearly defined, but the net income from the transformation of scientific and technological achievements such as new product sales, technical services and technical consultation is not clearly defined, and its value is difficult to measure. In addition, the research and development of some scientific and technological projects is based on the original achievements, and the incremental value of the achievements is not easy to calculate. In addition, in the actual management of science and technology projects, the value of scientific and technological achievements is not clearly marked in the contracts of technology transfer, service and consultation between some central enterprises, so it is impossible to calculate the net income according to the calculation method stipulated in relevant national laws and policies, which is difficult to implement at the operational level.

\subsection{The Supervision and Evaluation of Medium and Long-Term Incentive Policies Are Not in Place}

At present, the popularization and implementation of medium and long-term incentive policies for stateowned science and technology enterprises are not in place, and there are concerns and practical difficulties in policy implementation, such as weak management foundation of enterprises, fear of loss of state-owned assets, and difficulty in evaluating policy effectiveness, which affect the progress and intensity of enterprises in promoting policy implementation.

First, the enterprise management foundation and management ability are insufficient. The implementation of medium-and long-term incentives is closely related to the management foundation and management ability of enterprises, such as labor and employment, personnel management and salary distribution. Some enterprises have not yet established labor employment, personnel management and salary distribution mechanisms that are compatible with the modern enterprise system and market economy. In addition, due to lack of experience in the specific implementation process, it is difficult to quantify the incentive targets and operate them. Second, most enterprises have not yet built a perfect internal governance structure, and it is difficult to formulate and implement equity incentive schemes. The medium and long-term incentive mechanism has a strong dependence on the modern enterprise system, especially the equity incentive, which has higher requirements for the standardization of corporate governance structure and management. Third, the executive power of senior managers is insufficient. Due to the assessment requirements of the party and government leading bodies, it is difficult for most senior managers of stateowned enterprises to enjoy the equity and dividend incentive policies. At the same time, due to the fear of the loss of state-owned assets, they are worried about accountability afterwards, which leads to the lack of motivation in promoting equity incentives and a 
conservative wait-and-see attitude. Fourth, the supervision and evaluation of medium and long-term incentive policies are insufficient. The medium-and long-term incentive policies have gone through a certain period from pilot operation to popularization and implementation, and some policy and operational problems and obstacles have gradually emerged. However, there is still no long-term mechanism for tracking and evaluating the medium-and long-term incentives of science and technology enterprises, and it is difficult to dynamically grasp the implementation and demand changes of medium-and long-term incentives of science and technology enterprises and improve the policy system in a targeted manner [5].

\section{SUGGESTIONS ON MEDIUM AND LONG-TERM INCENTIVE OF STATE- OWNED SCIENCE AND TECHNOLOGY ENTERPRISES}

\subsection{To Further Strengthen Policy Support and Overall Coordination}

First, study and formulate relevant supporting management measures. In view of the policy ambiguities, difficulties and risks in the current medium-and long-term incentive process, research and formulate corresponding supporting policies and management measures, focusing on solving three problems: First, enhance the guidance of scientific and technological innovation. Increase support for forwardlooking research on the basis of scientific and technological innovation, start-ups and major projects, appropriately relax the operating performance requirements of science and technology enterprises, and explore the scientific research investment of central enterprises as profits into the assessment; Second, the mismatch between responsibility and income subject. Judging from the current policy implementation, the main beneficiaries of equity incentive are the internal scientific and technological leaders of enterprises, while the leaders of enterprises are worried about the loss of state-owned assets and lack of motivation. It is suggested that relevant measures should be introduced, and quantitative indicators such as improving the internal governance structure of the company and promoting the transformation and implementation of scientific and technological achievements should be included in the assessment management measures of the leadership team. Third, relax the restrictions on the number of enterprises as legal persons. For outstanding scientific and technological achievements, we will actively guide scientific research personnel to take parttime jobs or leave their posts to start businesses with scientific and technological achievements, and encourage central enterprises to set up new scientific and technological companies without being limited by the number of legal persons. Fourth, in view of the problem that the shareholding platform cannot enjoy tax incentives, we will step up deployment, research and issue relevant policies, and explore ways to formulate incentives for indirect shareholding to enjoy deferred tax incentives.

The second is to strengthen the connection and coordination with relevant laws and policies. In accordance with the Law on Promoting the Transformation of Scientific and Technological Achievements and the Notice of the General Office of the Central Committee of the Communist Party of China and the General Office of the State Council on Several Opinions on Implementing the Distribution Policy Oriented to Increasing Knowledge Value, the relevant management measures of state-owned assets were revised and improved, the examination and approval authority of state-owned intangible assets was further decentralized, the filing procedures were simplified, a fault-tolerant mechanism was established, and a list of fault-tolerance, error correction, exemption and punishment was established to improve the transformation efficiency of scientific and technological achievements. Strengthen the connection between the relevant management measures of state-owned assets, coordinate and implement policies, further clarify the reward amount of equity and dividend incentives, and implement the requirement that "the cash reward for the transformation of scientific and technological achievements obtained by scientific research personnel shall be included in the total performance salary of the unit in the current year, but not subject to the total amount limit and not included in the total amount base", and formulate and issue specific operation measures to promote the implementation of each unit in place. In addition, the medium-and long-term incentive work of state-owned science and technology-based enterprises will be coordinated with the three-year action of stateowned enterprise reform, modernization of central enterprises' governance, three institutional reforms and the actions of central enterprises to improve the worldclass management, so as to strengthen the management system and management capacity of central enterprises, improve the internal governance structure, promote the implementation of medium-and long-term incentives in an orderly manner and promote each other.

\subsection{To Further Explore Ways and Means to Enrich the Company's Medium and Long- Term Incentives}

Different medium and long-term incentive methods have their own emphasis on incentive orientation, applicable objects, incentive binding degree, etc., and their incentive functions and effects are also quite different. It is suggested that the central enterprises should comprehensively consider the enterprise system 
and explore ways and means to enrich the medium and long-term incentives. First, expand the scope of implementation of medium and long-term incentives in an orderly manner and increase incentives. On the one hand, the long-term incentive experience of mature science and technology enterprises, such as incentive scheme, management mode and risk management and control, has been refined and summarized, and enterprises with the same nature and similar business development have been selected for promotion, gradually expanded to enterprises outside the pilot, and further expanded the scope of implementing enterprises. On the other hand, considering a large number of market-oriented employment demands at present, some employees cannot get effective incentives due to their identity restrictions, so we can explore medium-and long-term incentives for strategic emerging industries, and explore bringing market-oriented employment into the scope of medium-and long-term incentives. The second is to explore the implementation of new medium and long-term incentives. On the basis of the current medium and long-term incentives of enterprises, sum up experiences and lessons in a timely manner, and strengthen and consolidate the effectiveness of medium and long-term incentives; At the same time, actively explore new medium and long-term incentives. The third is to explore the combination of long-term incentives for innovation. For example, we can explore the combination of dividends and equity incentives in science and technology enterprises with project investment, and adopt incentive methods with different risk levels for different levels of personnel in scientific research teams, and achieve different incentive purposes for different incentive objects with different incentive and binding degrees.

\subsection{To Further Increase the Publicity and Guidance of Medium and Long-Term Incentives and Exchange Experiences to Enhance the Effectiveness of Policies}

First, to strengthen policy propaganda and communication and make full use of various channels, such as SASAC meeting, meeting of heads of central enterprises and think tank alliance of central enterprises, to strengthen publicity and exchange of experiences on policy documents related to medium-and long-term incentives, ensure that central enterprises fully understand the spirit and operational requirements of medium-and long-term incentives, further deepen their understanding and support for medium-and long-term incentives, and provide a good environment for the implementation of medium-and long-term incentives. The second is to strengthen the research on the effect of policy implementation and summarize the experience. On the one hand, investigate and study the problems and risks faced by central enterprises in the process of medium and long-term incentive implementation, strengthen theoretical and methodological research, and further enhance policy foresight and guidance; On the other hand, we should sort out the typical experiences and advanced models of central enterprises in the medium and long-term incentive process, strengthen experience summarization and exchange, further study and popularize advanced models, and expand the influence of medium and long-term incentive.

\section{CONCLUSION}

The key to scientific and technological innovation lies in people. Since the 18th National Congress of the Communist Party of China, the relevant policies on the incentive mechanism of state-owned science and technology enterprises have been introduced one after another, and the pilot policies of equity and dividend incentive have gradually matured and spread to the whole country. With the implementation of the policy, the scope of medium and long-term incentives is expanding, the methods are becoming richer and more diversified, and the exploration and practice are deeper, which provides a strong support for comprehensively improving the vitality, innovation and competitiveness of state-owned enterprises and promoting the highquality development of state-owned enterprises.

\section{ACKNOWLEDGMENTS}

This research was supported by the State Grid Corporation of China science and technology project "Research on talent supply and demand analysis model and supply strategy suitable for company strategy".

\section{REFERENCES}

[1] L.S. Zhou. Research on the medium and long-term incentive mode of state-owned enterprises [N] Economic Information Daily, 2018-09-03(007).

[2] S.F. Yuan. New economic era needs new enterprise incentive theory-the latest development of foreign research [J] Journal of Zhongnan University of Economics and Law, 2012, (05):76-83+144.

[3] S. Yang. Relevant policies, practices and suggestions for state-owned enterprises to carry out equity and dividend incentives for scientific and technical personnel [J] China Human Resources Development, 2016, (20):22-29+76.

[4] Z. Wu. Research on salary incentive mechanism of state-owned enterprises [J] Human Resources Management, 2017, (11):59-61.

[5] Z.M. Xie, D.X. Xue, J. Dong. Summary of theoretical research on equity incentive [J] industrial technology and economy, 2007, 26(03):4-6. 